\title{
The Clinicians' Skills, Capability, and Organisational Research Readiness (SCORR) Tool
}

\author{
* Heather Iles-Smith ${ }^{\mathrm{ab}}$, Carole Burnett ${ }^{\mathrm{ab}}$, Denise H. Ross ${ }^{\mathrm{ab}}$, Heidi J. Siddle ${ }^{\mathrm{ab}}$ \\ ${ }^{a}$ Leeds Teaching Hospitals NHS Trust, United Kingdom; ${ }^{b}$ University of Leeds, United Kingdom
}

\begin{abstract}
A research-active healthcare workforce contributes to improved quality of care. Clinicians may be unaware that they are applying early research skills during their everyday practice. Greater understanding of their level of research attainment may improve their awareness and confidence in their research skills. This article describes the development of the Clinicians Skills, Capability, and Organisational Research Readiness (SCORR) Tool, a simple innovation that assesses and captures research skills and attainment at 1) clinician, and 2) organisational level. The SCORR Tool was initially developed to assess levels of research attainment and to promote discussion during annual appraisals for podiatrists working across secondary and community care in a northern region of England. The levels (1 to 5) of attainment recognise UK Health and Care Professions Council (HCPC) registration requirements for chiropodists/podiatrists (Standards 12 to 14). Following testing and feedback, research levels were adapted (Levels 0 to 5) to accommodate all healthcare professionals (with the exception of doctors and dentists). The SCORR Tool may be used individually by clinicians, or in collaboration with their manager, to better understand the level of research attainment and to prompt discussion to increase research activity. It may also be used across a workforce (e.g. during an appraisal) to understand the organisational research readiness. The SCORR Tool requires additional testing and evaluation to validate it as a tool for use across a variety of organisational environments.
\end{abstract}

Keywords: appraisals; clinician research readiness; organisational research readiness; research skills attainment

\section{Introduction}

It is recognised that evidence-based practice (EBP) constructed on sound research findings is the bedrock of high-quality person-centred care and improved outcomes (Boaz et al., 2015). Research-active healthcare organisations demonstrate improved patient outcomes and quality of care whether or not the patients themselves have participated in the research (Boaz et al., 2015).

*Corresponding Author: Dr Heather Iles-Smith, PhD. MSc. RGN. Leeds Teaching Hospitals NHS Trust and School of Healthcare, Baines Wing, University of Leeds, LS2 9JT United Kingdom

Email: heather@iles-smith.co.uk

Journal URL: https://publications.coventry.ac.uk/index.php/pblh

Iles-Smith, H., Burnett, C., Ross, D. H., \& Siddle, H. J. (2019). The clinicians' Skills, Capability, and Organisational Research Readiness (SCORR) tool. International Journal of Practice-based Learning in Health and Social Care, 7(2), 57-68. DOI 10.18552/ijpblhsc.v7i2.644 Access article is distributed under the terms of the Creative Commons Attribution Attribution-Non-Commercial No Derivatives 4.0 International License (https://creativecommons.org/licenses/by-nc-nd/4.0/ ), which permits unrestricted non-commercial use, distribution, and reproduction in any medium, provided the original work is properly cited and is unaltered. 
The requirement to support, contribute to and utilise research within healthcare is becoming accepted internationally. Within the United Kingdom (UK) National Health Service (NHS) Constitution, research is seen as a core part of business and is "integral to delivering innovative high quality patient care" (Department of Health, 2015). The ability of organisations such as the NHS to develop and maintain research activity for the benefit of patients is predicated on a well-trained and motivated workforce with the appropriate research knowledge and skills to lead and develop research (Health Education England, 2014).

However, developing early research skills and gaining confidence to apply research and EBP in preparation for becoming research active can often feel daunting for those involved in care on a day-today basis, yet clinicians often apply early research skills, such as critically questioning and appraising care, or may be involved in local audits and service or quality improvement projects without realising that these skills are helpful starting points in becoming research confident. Understanding that these skills are all relevant and contributory to building confidence related to undertaking research is a helpful way for individuals to develop knowledge and experience.

\section{Background}

A positive research culture including the promotion, conduct and use of research within healthcare services is reportedly an important factor in contributing to the highest standards of care excellence within healthcare organisations (Clarke \& Loudon, 2011). There are numerous ways for clinicians to be involved with research, from supporting the delivery of research to integrating research into practice and/or progressing to a personal clinical academic career (CAC). Developing a CAC requires integration between a practitioner's area of clinical practice and academic research pursuit, and ultimately results in the individual becoming a research leader within their field of practice.

Clinicians may often integrate research within their practice and regularly demonstrate early research skills without realising that this is the case. Likewise, healthcare organisations may not have sight of the general research activities and skills of their workforce and may not have mechanisms to identify these skills and resources across the workforce. This limits the ability of managers and organisations to identify this talent to support them in their development as potential future researchers, and reduces the opportunity to apply these skills to support the development of others thereby growing skills within the workforce.

Currently within the Nursing, Midwifery, Allied Healthcare Professions (NMAHPs) and other nonmedical professions, there is currently an under-representation of high-quality researchers and research (NIHR, 2019). It is likely that this is partly due to insufficient relevant role models with the required high levels of academic expertise and the advanced clinical training and experience necessary to engage, inspire, mentor and coach those who show an interest and talent in developing as clinical researchers. It is a known UK issue as highlighted by the Council of Deans for Health (Baltruks \& Callaghan, 2018) and the National Institute of Health Research (NIHR, 2019). Westwood \& Richardson (2014) have previously described a helpful range of Clinical Academic Roles at different stages of the Clinical Academic Career Ladder.

Less well defined in the literature are the early research skills that healthcare staff (particularly experienced clinicians) demonstrate in their everyday practice. These may be invisible to both the individual and the employing healthcare organisation due to a lack of simple research-skills assessment mechanisms at clinician and organisation level. The aim of this article is to outline an innovation developed with the intention of enabling clinicians (with the engagement of their manager) to assess their level of research skills and attainment and to promote engagement in research activity and CACs. This mechanism can also be used at organisational level to benchmark the research skills, activities and attainment of the workforce more effectively at an organisational level. 


\section{Method}

\section{Initial development of the SCORR Tool}

The SCORR Tool was established by the Leeds Clinical and Academic Podiatry (CAP) Network; a collaboration between clinicians in the Leeds NHS community and secondary care settings and a worldleading AHP research group at the University of Leeds.

The overarching aim was to produce a toolkit that could be used during the annual appraisal of clinical staff with the intention of opening a dialogue between appraisers and appraisees to promote the use of evidence-based practice and to encourage research activity. The five levels of attainment recognised the standards set out by UK professional registration body the Health and Care Professions Council (HCPC) and their requirements of podiatrists (Health and Care Professions Council, 2013) through to acknowledging those clinicians who are research active and leading the generation new knowledge. HCPC standards 12, 13 and 14 (Table 1) relate to the clinicians' research engagement, skills and attainment that all podiatrists are required to achieve (HCPC, 2013). Although this is required by the UK regulatory body, to our knowledge currently tools are not available for podiatrists, or other UK clinical professional groups, to assess levels of these particular research functions. Likewise, both professional groups and healthcare organisations are unable to identify 'hot spots' of high levels of competency and proficiency, or areas that are underdeveloped and require additional support, due to a lack of a simple systematic assessment tool.

\begin{tabular}{|c|c|}
\hline $\begin{array}{l}\text { Standard } \\
\text { number }\end{array}$ & Details of each standard \\
\hline \multicolumn{2}{|c|}{ 12. Be able to assure the quality of their practice } \\
\hline 12.1 & $\begin{array}{l}\text { be able to engage in evidence-based practice, evaluate practice systematically and } \\
\text { participate in audit procedures }\end{array}$ \\
\hline 12.2 & $\begin{array}{l}\text { be able to gather information, including qualitative and quantitative data that helps to } \\
\text { evaluate the responses of service users to their care }\end{array}$ \\
\hline 12.3 & $\begin{array}{l}\text { be aware of the role of audit and review in quality management, including quality } \\
\text { control, quality assurance, and the use of appropriate outcome measures }\end{array}$ \\
\hline 12.4 & be able to maintain an effective audit trail and work towards continual improvement \\
\hline 12.5 & $\begin{array}{l}\text { be aware of, and be able to participate in, quality assurance programmes, where } \\
\text { appropriate }\end{array}$ \\
\hline 12.6 & $\begin{array}{l}\text { be able to evaluate intervention plans using recognised outcome measures and revise the } \\
\text { plans as necessary in conjunction with the service user }\end{array}$ \\
\hline 12.7 & $\begin{array}{l}\text { recognise the need to monitor and evaluate the quality of practice and the value of } \\
\text { contributing to the generation of data for quality assurance and improvement } \\
\text { programmes. }\end{array}$ \\
\hline \multicolumn{2}{|c|}{ 13. Understand the key concepts of the knowledge base relevant to their profession } \\
\hline 13.1 & $\begin{array}{l}\text { be aware of the principles and applications of scientific enquiry, including the evaluation } \\
\text { of treatment efficacy and the research process }\end{array}$ \\
\hline \multicolumn{2}{|c|}{$\begin{array}{l}\text { 14. Be able to draw on appropriate knowledge and skills to inform practice determine } \\
\text { appropriate actions }\end{array}$} \\
\hline$[\ldots]$ & {$[\ldots]$} \\
\hline 14.16 & $\begin{array}{l}\text { be able to use research, reasoning and problem solving skills to determine appropriate } \\
\text { actions }\end{array}$ \\
\hline 14.17 & recognise the value of research to the critical evaluation of practice \\
\hline 14.18 & be aware of a range of research methodologies \\
\hline 14.19 & be able to evaluate research and other evidence to inform their own practice \\
\hline
\end{tabular}

Table 1: HCPC (2013) Standards of Proficiency Chiropodists/Podiatrists 
The Leeds CAP Network agreed the 'Steps' (later to become Levels) of an assessment tool that would differentiate those who are research engaged from those who have taken the next steps to becoming research active and ultimately clinical academic leaders. Consultation with approximately fifty podiatrists, across a community healthcare and secondary healthcare NHS Trust within the same geographical region, was undertaken to determine if the tool was usable and if any examples of additional descriptors/ways/evidence to demonstrate meeting the criteria for each step could be provided.

Forty-one podiatrists (Band 5 to Band 8A) and three podiatry assistants (Band 3), working in clinical practice from both Trusts during 2017, were asked to determine their current level of research involvement (1 to 5). Participants were asked two questions regarding usefulness and applicability of the levels.

Figure 1: Examples of qualitative responses to Question 1

\section{Question 1: Do the levels make sense and seem appropriate?}

\section{Examples of two responses:}

"Just not sure if the levels are step-by-step approach (meant to be) or if you are able to be a bit of a part of, for example Level one and three but miss the step two (hope that makes sense)."

"I think all the levels are certainly achievable; up until Level 5 as not all will want to conduct research. Not sure if Level 5 can be changed."

Figure 2: Examples of qualitative responses to Question 2

Question 2: Are there any additional descriptors/ways/evidence to demonstrate meeting the criteria for each level?

Examples of two responses:

"Could the criteria be made more relevant to clinicians working in community base where less opportunity for traditional research and more focus on smaller, local orientated work?"

"Read journal articles and feed back in team meetings on findings and evidence."

The SCORR Tool steps were then refined (Table 2), based on the anonymous qualitative feedback (Figures 1 and 2) from participating podiatrists (Bands 3 to 8a). The refined version was then shared with podiatrists and received positive feedback from staff, who suggested it was a useful tool in helping them and their managers to assess research engagement and attainment and to promote discussion to identify opportunities for further research engagement. 


\begin{tabular}{|l|l|l|l|}
\hline \multicolumn{2}{|l|}{ Level of attainment } & Criteria & Examples in practice \\
\hline $\begin{array}{l}\text { Research } \\
\text { engaged }\end{array}$ & Step 1 & $\begin{array}{l}\text { Implementing new } \\
\text { knowledge into } \\
\text { practice }\end{array}$ & $\begin{array}{l}\text { Personal development to support meeting the } \\
\text { minimum standards identified by the HCPC and } \\
\text { key pledges in the NHS constitution } \\
\text { (Department of Health, 2015) }\end{array}$ \\
\cline { 2 - 4 } & Step 2 & $\begin{array}{l}\text { Share awareness of } \\
\text { new knowledge }\end{array}$ & $\begin{array}{l}\text { Shares new knowledge with colleagues, patients } \\
\text { and the public }\end{array}$ \\
\cline { 2 - 4 } & Step 4 & $\begin{array}{l}\text { Synthesis of new } \\
\text { knowledge } \\
\text { knowledge with the } \\
\text { support of others }\end{array}$ & $\begin{array}{l}\text { Leading and making decisions to implement } \\
\text { change using more structured approaches. }\end{array}$ \\
\cline { 2 - 4 } & Step 5 & $\begin{array}{l}\text { Leading the } \\
\text { generation of new } \\
\text { knowledge }\end{array}$ & $\begin{array}{l}\text { Actively participating in research delivery } \\
\text { clinical research }\end{array}$ \\
\hline
\end{tabular}

Table 2: Research attainment (Steps 1 to 5) for podiatrists

\section{Enhancing the SCORR Tool to include more professional groups}

The positive findings from the podiatry group were used to broaden the use of SCORR with wider professional groups. The 'Steps' were adapted to reflect groups including all HCPC-registered professions and Nurses and Midwives who are required, in the UK, to register with the Nursing, Midwifery Council (NMC). Other professional groups (Table 3) were also included. For the purposes of this article, the focus will be the largest professional groups - nursing, midwifery and AHPs - required to register with NMC and HCPC.

\begin{tabular}{|l|l|l|}
\hline *Professional group & Regulatory body & Abbreviation \\
\hline Allied Health Professions & Health and Care Professions Council & HCPC \\
\hline Nurses and Midwives & Nursing, Midwifery Council & NMC \\
\hline Pharmacists & General Pharmaceutical Council & GPhC \\
\hline Healthcare Scientists & Academy for Healthcare Science & GHCS \\
\hline Optometrists & General Optical Council & GCC \\
\hline Chiropractors & General Chiropractic Council & GOSC \\
\hline Osteopaths & General Osteopathic Council & \\
\hline
\end{tabular}

* 'Professional group' may not denote all professions regulated by each council; a full list of professions can be found on each Council website.

Table 3: Professional groups included within the SCORR Tool

All HCPC-registered professions are required to engage with research as demonstrated by HCPC Standards of Proficiency for Chiropodists/Podiatrists (Table 1). Conversely, the NMC 'Code' (Standards of Practice) (Nursing \& Midwifery Council, 2018) does not specify research engagement, but Standard 6 requires nurses and midwives to "always practise in line with the best available evidence" (Table 4). 


\begin{tabular}{|l|l|}
\hline $\begin{array}{l}\text { Standard } \\
\text { number }\end{array}$ & Details of each standard \\
\hline 6. Always practise in line with the best available evidence. To achieve this, you must: \\
\hline 6.1 & $\begin{array}{l}\text { make sure that any information or advice given is evidence based - } \\
\text { including information relating to using any health and care products or services }\end{array}$ \\
\hline 6.2 & maintain the knowledge and skills you need for safe and effective practice \\
\hline
\end{tabular}

Table 4: Nursing \& Midwifery Council (2018) Code, Standard 6

The SCORR Tool was further adapted with the NMC Code in mind including broader terminology such as involvement in evidence-based practice (EBP) or research (Table 5) rather than purely research. The Steps were also changed to 'Levels' of attainment and an additional 'Level 0 - Requires support to gain knowledge from evidence based practice/research and apply it to practice' was also included to capture those who believed that currently they were not meeting minimum standards and required support to develop.

Suitability of the SCORR Tool levels, and its use across the registered workforces during each clinician's appraisal, was captured at two face-to-face events with fifty senior clinicians. The SCORR tool levels were reviewed by senior nurses (45), midwives (3) and AHPs (2). Information was collected using the two questions: 1) Do the levels make sense and seem appropriate? 2) are there any additional descriptors/ways/evidence to demonstrate meeting the criteria for each level?

Overall, participants responded positively to SCORR and believed that it may be a useful means of identifying good practice and areas of the workforce requiring development in terms of research skills and engagement. Two individuals asked for reassurance that the findings from the SCORR Tool would not be linked to pay and conditions or those reporting 'Level 0' would not receive punitive action. Reassurance was offered that neither of these actions were the intentional use of the SCORR Tool.

\section{Discussion}

To our knowledge this is the first tool that has been developed to assess the current 'Skills, Capability, and Organisational Research Readiness (SCORR)' of non-medical registered health professionals working within healthcare. The SCORR Tool intends to open a dialogue between clinicians and their managers to promote the use of EBP and encourage research activity in the clinical environment to benefit patient care.

Research is typically held 'in an ivory tower' by both clinicians and clinical managers. The SCORR Tool was developed to be formally implemented during 'appraisal season'. It is intended to enable a conversation between managers and health professionals so that, as well as identifying current 'levels' of attainment, development opportunities can be discussed, particularly for those who may wish to explore a clinical academic career.

Implementing the SCORR Tool as part of a clinician's annual appraisal process normalises research and EBP as a key part of everyday clinical practice. For those starting on their research journey a first helpful step may be for them to identify their current level of research knowledge and experience; the SCORR Tool offers a quick and systematic means to do this. It also enables identification of areas of their knowledge and experience that can be developed to the next 'Level', leading to increased skills and confidence. 


\begin{tabular}{|c|c|c|}
\hline Level & Criteria & Example \\
\hline Level 0 & $\begin{array}{l}\text { Does not meet Levels } 1-5 \text { and } \\
\text { requires support to gain } \\
\text { knowledge from evidence } \\
\text { based practice/research and } \\
\text { apply it to practice. }\end{array}$ & Does not meet the minimum standards identified by their professional registration body \\
\hline Level 1 & $\begin{array}{l}\text { Gains new knowledge from } \\
\text { EBP/ research and applies it to } \\
\text { practice. Clinician meets the } \\
\text { minimum standards identified } \\
\text { by their professional } \\
\text { registration body* and key } \\
\text { pledges in the **NHS } \\
\text { constitution }\end{array}$ & $\begin{array}{l}\text { *Individual is referred to their relevant professional registration guidance. } \\
\text { **NHS Constitution of England (Department of Health, 2015): The NHS aspires to the highest standards of excellence and } \\
\text { professionalism through its commitment to innovation and to the promotion, conduct and use of research to improve the } \\
\text { current and future health and care of the population. The NHS also commits (through their staff) to inform the patient of } \\
\text { research studies in which they may be eligible to participate. }\end{array}$ \\
\hline Level 2 & $\begin{array}{l}\text { Shares awareness of new } \\
\text { knowledge (from } \\
\text { EBP/research) with colleagues, } \\
\text { patients and the public and } \\
\text { challenges practice to improve } \\
\text { patient care. }\end{array}$ & $\begin{array}{l}\text { - Shares new knowledge (e.g. research, evidence based and clinical) with colleagues, patients and the public, for example } \\
\text { through staff meetings, journal clubs, appropriate social media, patient consultations and expert patient groups. } \\
\text { - Shares updates on local and national polices and guidelines e.g. Leeds Care Pathway, NICE guidelines. } \\
\text { - Positively challenges practice to improve patient care, for example through new knowledge gained, skilled clinical } \\
\text { observation, reading and evaluating relevant literature. }\end{array}$ \\
\hline Level 3 & $\begin{array}{l}\text { Uses research findings to } \\
\text { support change and service } \\
\text { development to address } \\
\text { clinical challenges (e.g. } \\
\text { contributes to established }\end{array}$ & $\begin{array}{l}\text { - Supports the implementation of research into practice e.g. through journal clubs, literature reviews, and generating local } \\
\text { policy documents. } \\
\text { - Contributes to established research groups/networks. }\end{array}$ \\
\hline
\end{tabular}

\section{Table 5: SCORR clinician clinical research skills levels 0 to 5 for non-medical professions}




\begin{tabular}{|c|c|c|}
\hline $\begin{array}{l}\text { Level } 3 \\
\text { (continued) }\end{array}$ & $\begin{array}{l}\text { clinical networks, research } \\
\text { groups, journal clubs, literature } \\
\text { reviews, development of } \\
\text { local/national policies). }\end{array}$ & $\begin{array}{l}\text { - } \quad \text { Contributes to the development of local/national policies. } \\
\text { - Identifies and critiques relevant literature. } \\
\text { - Leads service development and changes through translation of research findings and implementing evidence-based } \\
\text { practice. }\end{array}$ \\
\hline Level 4 & $\begin{array}{l}\text { Actively undertakes own } \\
\text { research with the support of } \\
\text { others or supports the delivery } \\
\text { of research and disseminates } \\
\text { research outcomes locally. }\end{array}$ & $\begin{array}{l}\text { - Uses a structured approach to review the literature through critically appraising and synthesising evidence in order to } \\
\text { inform solutions that address clinical challenges. } \\
\text { - Understands research governance and adheres to regulatory requirements such as the UK Policy Framework for Health } \\
\text { and Social Care Research and Good Clinic Practice (GCP) as relevant. } \\
\text { - Actively participates in research delivery (e.g. identification and recruitment of participants, data collection, translating } \\
\text { new knowledge to improve patient care). } \\
\text { - Disseminates new knowledge locally, for example through conference abstract submission, written publications and } \\
\text { patients groups. }\end{array}$ \\
\hline Level 5 & $\begin{array}{l}\text { Leads the generation of new } \\
\text { knowledge through research } \\
\text { (e.g. actively develops and } \\
\text { leads clinical research, } \\
\text { engages with research } \\
\text { collaborators, obtains research } \\
\text { funding, disseminates research } \\
\text { nationally/internationally). }\end{array}$ & $\begin{array}{l}\text { - Uses own clinical experience and patient engagement to identify clinically relevant research questions as the basis for } \\
\text { their own research and to inform the appropriate research agenda. } \\
\text { - Develops and maintains research collaborations within and beyond their professional group. } \\
\text { - Obtains appropriate funding to support research activity. } \\
\text { - Disseminates research through publication and national/international conference presentations. } \\
\text { Develops and supports research capacity in others. }\end{array}$ \\
\hline
\end{tabular}

Table 5: [Continued] SCORR clinician clinical research skills levels 0 to 5 for non-medical professions 
The SCORR Tool allows individuals to recognise what activities they are already engaged with or have undertaken previously that have led to increased knowledge and skills; this was highlighted during consultation with the podiatry teams. Clinicians may often be research-active and research aware and engaged in developing early research skills (Figure 3) as part of their everyday practice without realising it. Development can be tailored to individuals to enable their career progression as a research-active and aware clinician or as a clinical academic contributing to the body of evidence.

Figure 3: Research skills development activities

\begin{tabular}{|c|}
\hline Audit \\
is designed to test whether \\
an established service is \\
meeting a defined standard
\end{tabular}

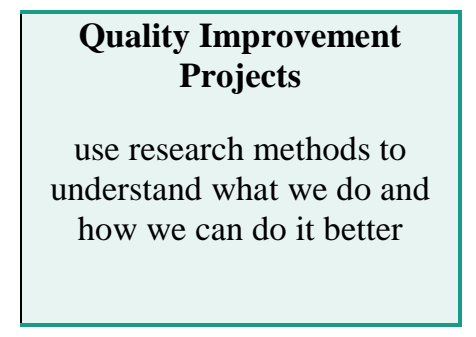

\section{Patient and Public Involvement}

All the time, we ask our patients how we can make our services better
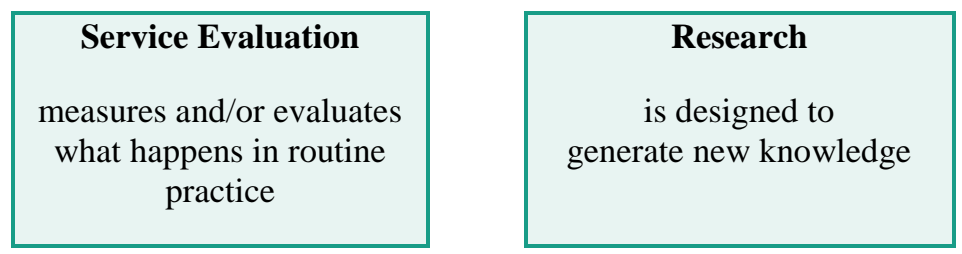

\begin{tabular}{|c|}
\hline Clinically Appraised \\
Topic \\
summarising the best \\
available research \\
evidence related to a \\
specific clinical question \\
\hline
\end{tabular}

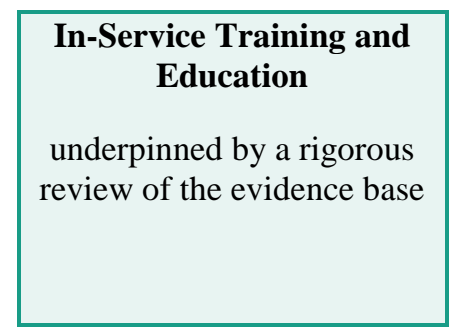
Post Graduate Education
underpinned by the current evidence base and delivered by our HEI partners

Clinical academics often report that, in the early stages of their careers, they were naturally curious, frequently challenging practice decisions and pathways (Carrick-Sen et al., 2016). They were also avid readers of the medical and practice-based literature and active within their work-based journal clubs. The environment that this practice fosters usually results in bright ideas for service development, evaluation, audit and research; it is important that the differences between these areas are understood and they have been captured in the SCORR Tool. In addition to supporting the development of the individual, the SCORR Tool offers a quick and easy opportunity to gain a workforce-wide understanding of clinical research involvement.

The SCORR Tool was not specifically designed to assess the research culture of an organisation, as numerous validated tools are already available for this purpose. One such tool, the Research and Development (R\&D) Culture Index, an 18-item questionnaire, has been applied and validated for use across numerous different environments (Watson et al., 2005). It offers sufficient complexity of data to generalise and draw conclusions across a workforce. However, its limitations are similar to those of other questionnaires, and include poor response rates due to challenges with cascading the tool to target groups, and the requirement for respondents to be self-motivated to complete the tool (Edwards, 2010).

Although a simple tool such as the SCORR is limited to high-level information, when used within the appraisal process amalgamation of data across the workforce may lead to identification of 'hot spots' of good practice and talent with research skills being identified. Nurturing this talent may well lead to the developing or mentoring of others wishing to pursue a clinical academic career. Having workforce-wide 
knowledge of staff skills also means organisations can share and utilise areas of good 'research practice' to support others and build research capacity in areas that are not engaged.

Inclusion of the broader professional groups, in particular nursing and midwifery, within the refined version of the SCORR Tool posed some challenges due to the differences in the professional standards required by HCPC and NMC. Currently the NMC do not require nurses, midwives and nursing associates to specifically participate in or support research. Standard 6 (Table 4) suggests that clinicians are required to engage with evidence-based practice (Nursing \& Midwifery Council, 2018), but does not directly require research engagement. In contrast, Allied Health Professionals and other professionals registered with the HCPC are specifically required to support research, service improvement, audit and EBP (Table 1) (HCPC, 2013).

This stark contrast in the UK standards required by HCPC and NMC is mirrored by the current National Institute for Health Research (NIHR) personal research funding application rates and successful awards. During the last decade greater progress has been made by AHP groups compared to nurses and midwives in submitting high-quality fundable personal research fellowship applications to the NIHR (National Institute for Health Research, 2019). This is despite nursing and midwifery being the larger UK professional group. The reason for nurses and midwives failing to secure these funding awards is multifaceted and complex. However, the underpinning of the professional registration standards may well play some part in either defining or reflecting the current cultures within the professions. The future addition of research within the NMC code may well go some way to promoting engagement of the professions with research, thereby normalising research as part of day-to-day practice and improving care.

\section{Limitations and future research}

We recognise that there are limitations to the work presented in this article. We are pragmatic in the use of the SCORR Tool but have demonstrated that it is feasible to produce a tool which can be used to measure the 'quantity' of research undertaken within a healthcare environment. We understand that further work is required to produce a tool that would be transferable to all professions in a variety of healthcare environments.

The major limitation of the SCORR Tool is the lack of validation either within one professional group or institution, or across the non-medical workforce as a whole. The current SCORR Tool resulted as a consensus agreement between a small number of healthcare professionals within two healthcare Trusts in the same geographical region. The selection of senior healthcare professionals to validate the suitability of the Tool may have led to unknown bias in the understanding of the SCORR levels due to experience gained through their employment history. Validating the levels with a wider group of healthcare professionals, by performing a multi-centre Delphi consensus study of registered healthcare professionals from the appropriate health professions, would provide evidence to confirm the appropriateness of the levels defined in the SCORR Tool, and determine whether the language used in the SCORR Tool was appropriate for use. This would mitigate nuances that may result from geographical location or profession-related jargon.

Additionally, the level of research understanding from an individual may or may not represent the research culture of the Trust; individuals who are research active often achieve their success or knowledge through their own drive, undertaking additional study or work to further their own careers. Individual success may not reflect the Trust as a whole in research endeavours. On the other hand, Trusts may offer a supportive research culture to staff members but individuals may choose not to engage (or do not think that they are entitled to be research active), and their scoring may underplay that of the Trust. An objective tool is required to identify the quantity of the research culture of the Trust and correlate that with the results of the staff. In the absence of such a tool, a more representative result for individuals and the Trust as a whole may be achieved by performing this exercise over a period of time. This would allow for: 
(1) Bedding-in of the tool so that staff become accustomed to, and familiar, with the terminology used in the SCORR levels;

(2) A better understanding of the meaning of the levels, so that staff can reflect on their true level in the year preceding their appraisal, as opposed to making a snap decision as to their level;

(3) Removal of a self-imposed fear of research, allowing an individual to think in the wider context of their clinical practice;

(4) Individuals to investigate and engage with the opportunities that are available within their Trust.

Determination of the SCORR level by the individual is self-reported, which may lead to variation in results as each individual interprets their involvement or knowledge differently from others. Validation of the level selected could be achieved by asking for examples of practice that would confirm their selection. Further validation could be achieved by educating appraisal managers to provide them with tools to ensure an appropriate selection of level by the individual.

\section{Conclusion}

The SCORR tool has been created to help individuals and their managers to establish a non-medical clinician's current level of research attainment, through the appraisal process. This creates an excellent opportunity for both clinician and manager to 'open the conversation' in relation to EBP and research. Central to the tool's development were the UK HCPC and NMC EBP, and research-related professional standards. This enables clinicians and managers to clearly associate the tool (and EBP and research) with everyday practice and potentially to normalise research as part of improving everyday care. Further work and development of the SCORR tool may also aide organisations to establish a high level of understanding of EBP and of the research attainment of the workforce.

\section{Acknowledgements}

We would like to acknowledge the contribution of the Leeds Clinical \& Academic Podiatry Network and members of the Leeds Research Leadership group and Research Capacity Building group for their continued support.

\section{ORCID}

Heather Iles-Smith:

https://orcid.org/0000-0002-0520-2694

Carole Burnett:

https://orcid.org/0000-0003-1406-0920

Heidi J Siddle: $\quad$ https://orcid.org/0000-0002-6015-332X

\section{References}

Baltruks, D., \& Callaghan, P. (2018). Nursing, midwifery and allied health clinical academic research careers in the UK. https://councilofdeans.org.uk/wp-content/uploads/2018/08/Nursingmidwifery-and-allied-health-clinical-academic-research-careers-in-the-UK.pdf

Boaz, A., Hanney, S., Jones, T., \& Soper, B. (2015). Does the engagement of clinicians and organisations in research improve healthcare performance: A three-stage review. BMJ Open, 5(12), e009415. https://doi.org/10.1136/bmjopen-2015-009415

Carrick-Sen, D., Richardson, A., Moore, A., \& Dolan, S. (2016). Transforming healthcare through clinical academic roles in nursing, midwifery and allied health professions: A practical resource for healthcare provider organisations. https://councilofdeans.org.uk/wpcontent/uploads/2019/02/AUKUH-Transforming-Healthcare.pdf 
Clarke, M., \& Loudon, K. (2011). Effects on patients of their healthcare practitioner's or institution's participation in clinical trials: a systematic review. Trials, 12(1), 1-10. https://doi.org/10.1186/1745-6215-12-16

Department of Health. (2015). The NHS constitution for England. https://www.gov.uk/government/uploads/system/uploads/attachment_data/file/480482/NHS_Co nstitution_WEB.pdf

Edwards, P. (2010). Questionnaires in clinical trials: Guidelines for optimal design and administration. Trials, 11(1), 2. https://doi.org/10.1186/1745-6215-11-2

Health and Care Professions Council. (2013). Standards of proficiency: Chiropodists/podiatrists. https://www.hcpc-uk.org/globalassets/resources/standards/standards-of-proficiency--chiropodists-and-podiatrists.pdf

Health Education England. (2014). Developing a flexible workforce that embraces research and innovation: Research and Innovation Strategy. https://www.hee.nhs.uk/sites/default/files/documents/HEE\%20research\%20and\%20innovation\% 20strategy.pdf

National Institute for Health Research. (2019). NIHR strategic review of training. https://www.nihr.ac.uk/explore-nihr/support/strategic-review-of-training.htm

Nursing \& Midwifery Council. (2018). The Code: Professional standards of practice and behaviour for nurses, midwives and nursing associates. https://www.nmc.org.uk/globalassets/sitedocuments/nmc-publications/nmc-code.pdf

Watson, B., Clarke, C., Swallow, V., \& Forster, S. (2005). Exploratory factor analysis of the research and development culture index among qualified nurses. Journal of Clinical Nursing, 14(9), 10391164 https://doi.org/10.1111/j.1365-2702.2005.01214.x

Westwood, G., \& Richardson, A. (2014). Clinical Academic Careers Pathway Capability Framework for nurses, midwives and allied health professionals. AUKUH. https://www.southampton.ac.uk/assets/centresresearch/documents/wphs/AUKUH-ClinicalAcademic-Careers-Capability-Framework-May-2014-4.pdf 